\title{
Levels of Rheumatoid Factor in Plasmodium Falciparum Malaria in Children and Its Association with Gender, Age and Parasite Density
}

\author{
Hien Sansan, Yeboah Oppong Richard, N'Guessan Koffi, Kouacou Amah Patricia Victorine, \\ Adou Honoré, Dassé Sery Romuald
}

Departement of Hematology-Immunology-Oncology, Faculty of Medical Sciences, Félix Houphouët Boigny University, Abidjan, Côte d'Ivoire

\author{
Email address: \\ hien_sansan73@yahoo.fr (S. Hien)
}

\section{To cite this article:}

Hien Sansan, Yeboah Oppong Richard, N'Guessan Koffi, Kouacou Amah Patricia Victorine, Adou Honoré, Dassé Sery Romuald. Levels of Rheumatoid Factor in Plasmodium Falciparum Malaria in Children and Its Association with Gender, Age and Parasite Density. International Journal of Immunology. Vol. 4, No. 6, 2016, pp. 46-51.doi: 10.11648/j.iji.20160406.11

Received: September 20, 2016; Accepted: October 6, 2016; Published: December 17, 2016

\begin{abstract}
Objectives: The rheumatoid factor (RF), like any antibody, may encounter in the body an antigenic specificity. It will then bind to an antigen by cross-reaction or an already formed immune complex. In this context, the RF may impede reactions of diagnosis with immunological principle (antigen-antibody reaction). The rheumatoid factor as well as anti-animal antibodies also reacts with the $\mathrm{Fc}$ portion of animal or human IgG of kits of reagents leading to false positive or false negative results. That's the reason why we wanted to have more information about its levels and its association with gender, age and parasite density in children with falciparum malaria. Methodology: It was a prospective study about 130 children of both sexes (M / F: 73/57; mean age: $4.78 \pm 3.48$ years), suffering from falciparum malaria and aged from 0 to 15 years old. Those children have been included in pediatric services of the University Hospital Center of Cocody and the General Hospital of Kumasi, both, in Abidjan. Venous blood samples were collected on EDTA for blood cells count, parasite densities, and identification of Plasmodium falciparum. The other blood samples collected without EDTA were used to measure Rheumatoid Factor levels. Giemsa-stained thin and thick blood films were analyzed by microscope for plasmodium species and parasite density. Hematological parameters were determined using hematology cell counter (Sysmex KX-21N). Slide agglutination test (RFlatex) was used for qualitative and quantitative detection of Rheumatoid Factor. Statistical analysis was carried out on a computer using Excel 2007 and Statistica 7.1. For all test p-value $<0.05$ below was considered significant. Results: During falciparum malaria, $30 \%$ of children in this study produced RF. The mean level of RF observed in children under 5 years was higher than those whose age was $\geq 5$ years but statically not significant $(p=0.07)$. We also found in children whose age was $\geq$ 5 years, negative correlation between the level of RF and parasite density, which was stronger than those under 5 years $(R=-$ $0.53, \mathrm{p}=0.006$ vs $\mathrm{R}=-0.23 \mathrm{p}=0.013)$. Most of children secreting Rheumatoid Factor were males $(69.23 \%)$ and had more risk than females $(\mathrm{OR}=3.35)$. Conclusion: This study showed that $30 \%$ of children in falciparum malaria secreted $\mathrm{RF}$. This autoantibody was associated with gender, age and parasite density.
\end{abstract}

Keywords: Falciparum Malaria, Rheumatoid Factor, Children

\section{Introduction}

Rheumatoid factor is a set of auto-antibodies. It is part of heterophil antibodies as well as human anti- animal antibodies and anti-idiotypes. This auto-antibody is usually $\operatorname{IgM}$ isotype but may be of another isotype ( $\operatorname{IgA}, \operatorname{IgG}, \operatorname{IgD}$, and $\operatorname{IgE}$ ). It usually characterizes auto immune diseases but it can also be encountered in other conditions. There are physiological RF (poly-reactive natural antibodies and of low affinity) and pathological RF (mono-reactive and of high affinity). These include monoclonal RF present in Waldenström's disease and chronic lymphocytic leukemia (they are associated with cryoglobulinemia) and polyclonal $\mathrm{RF}$ present in inflammatory and infectious diseases [1]. 
During malaria infection, Plasmodium develops escape mechanisms to host immune system [2], which leads to a generation of auto-antibodies which include Rheumatoid factor [3-7]. When there is an important chronic inflammatory reaction, various natural auto-antibodies (rheumatoid factors, anti phospholipids) can be produced independently of any autoimmune disease. For example, during endocarditis or chronic parasitosis (leishmaniasis, malaria), rheumatoid factors are detectable in about $30 \%$ of cases [8]. If the rheumatoid factor and anti-animal antibodies react with the Fc portion of animal or human IgG of kits of reagents, anti-idiotypic antibodies rather react with Fab portions [9]. Like any antibody, the RF may encounter in the body an antigenic specificity. It will then bind to an antigen by cross-reaction or an already formed immune complex. In this context, the RF may impede reactions of diagnosis with immunological principle (antigen-antibody reaction) and give false positive or false negative results [10-14]. These two aspects have been demonstrated by the work of Dassé et al [15] that showed that before the exhaustion of the rheumatoid factor in samples to be assayed, the percentages of false positives and false negatives were high. But after exhaustion of the RF, these percentages have dropped significantly. Other authors have shown that the values of RF could vary according to age, gender, sample type, diet and geographical location. Our study aims to assay the IgM isotype of the RF and to seek its relationship with age, gender and parasite density during Plasmodium falciparum malaria. Indeed Plasmodium falciparum malaria is by far the most common and deadliest especially in sub-Saharan children under 5 years. In addition its association with other bacterial infectious, viral or parasitic diseases, themselves generating rheumatoid factor could increase the rate of this factor and cause interference in immunoassays in children living in malaria-endemic area or affected by this parasitosis.

\section{Material and Methods}

This prospective cross-sectional study was carried out in Abidjan (Côte d'Ivoire) in the department of pediatric emergencies of the University Hospital in Cocody and at the general hospital in Kumasi. It included 130 boys and girls aged from 0 to 15 years, with a positive thick and thin blood smear with Plasmodium falciparum, meeting the inclusion criteria. These patients had no infection associated on clinical examination. For each patient, admitted to these departments and meeting our inclusion criteria, a survey form was filled in with the consent of a family member. The blood collected by venipuncture was collected in tubes containing EDTA to perform the thick blood smear, the blood film, the blood count $(\mathrm{CBC})$, and in dry tubes for the determination of rheumatoid factor. The determination of parasite density was done by counting the number of parasites in 200 leukocytes and assuming that the average WBC is $8000 / \mu 1$. The smear helped identify the parasite species and take into account only Plasmodium falciparum. The blood count was performed by means of Sysmex KX-21N. The parasitological and hematological examinations were performed in the emergency laboratory of the University Hospital in Cocody. The determination of the rheumatoid factor was performed by the semi-quantitative method of latex agglutination on card (FR-latex Spinreact) in the Laboratory of ImmunologyAllergology and Hematology of the University Hospital in Cocody. The statistical analysis of data was performed on Excel 2007 and Statistica 7.1. Software at the 5\% threshold. Averages, standard deviations, regression lines and correlation coefficients as well as the comparison of averages (Student test), were obtained with the same software.

\section{Results}

The study population consisted of $56.15 \%$ of males and $43.85 \%$ of females with a sex ratio of 1.28 . The mean age was $4.78 \pm 3.48$ years, with extremes ranging from 1 to 15 years. Children under 5 years were the majority with $61.54 \%$. It was noted $58.46 \%$ of severe forms of malaria. Anemia was present in $70 \%$ of cases. The mean hemoglobin level was $7.48 \pm 5.34 \mathrm{~g} / \mathrm{dl}$ with extremes ranging from 3 to $15 \mathrm{~g} / \mathrm{dl}$. Overall, the mean level of thrombocytes was $120.49 \pm 100.75$ $\mathrm{x} 10^{3} / \mu 1$ and that of leukocytes $11.81 \pm 6.55 \times 10^{3} / \mu 1$. In the distribution of patients of the study population according to rheumatoid factor (RF), 30\% of them secreted this factor that is less than a third of this population. They had a mean age of $4.59 \pm 3.45$ years, with ranging from 1 to 12 years. All were suffering from severe malaria. In Table 1, the distribution of the study population according to gender, rheumatoid factor, its levels and parasite density, showed that males were dominant (69.23\%) among subjects who secreted RF (R F+), while among those who did not secrete it, females were rather dominant $(52.75 \%)$. Considering gender as a risk factor, Table 1 allowed us to determine an Odd ratio (OR) of 3.35 that shows that males had 3.35 times higher risk of secreting RF compared to females during a malaria attack in children. In the same Table 1 the distribution of patients who secreted RF, according to gender and the mean levels of secretion, showed that both sexes (Male and Female) had respectively practically equal mean levels (12.89 vs. 12.67 $\mathrm{IU} / \mathrm{ml}$ ) with no statistically significant difference $(\mathrm{p}=0.46)$. The mean level of RF in all subjects who secreted it was $12.82 \mathrm{IU} / \mathrm{ml}$. About parasite densities according to gender (Table 1), the difference observed was not also significant ( $\mathrm{p}$ $=0.350)$. The Table 2 showed that majority of secreting subjects $(58.97 \%)$, were less than 5 years. These under 5 year-patients secreted a level of $14.09 \mathrm{IU} / \mathrm{ml}$, higher than that of those who had an age superior or equal to 5 years $(11.00$ $\mathrm{IU} / \mathrm{ml})$. However, this observed difference was not statistically significant $(p=0.07)$. It's the same for parasite densities $(\mathrm{p}=0.291)$. In Table 3 , among the 39 subjects who secreted RF, $22(56.41 \%)$ had a parasite density below 60000 Tpz / $\mu 1$ (Tpz: Trophozoite) and $17(43.59 \%)$ had a parasite density higher or equal to $60000 \mathrm{Tpz} / \mu \mathrm{l}$. For these two groups of parasitemia, the mean level of RF was higher for parasite densities below $60000 \mathrm{Tpz} / \mu \mathrm{l}$ that is $14.73 \mathrm{IU} / \mathrm{ml}$ compared to those greater or equal to $60000 \mathrm{Tpz} / \mu \mathrm{l}$ that is 
$10.35 \mathrm{IU} / \mathrm{ml}$. This observed difference was statistically significant $(p=0.018)$. Figure 1 revealed that the number of subjects secreting RF was inversely proportional to age. There was a statistically significant negative correlation $(\mathrm{R}=$ - 0.74, $\mathrm{p}<10^{3}$ ). This negative correlation confirms the results in Table 2 concerning the distribution of patients who secreted RF according to age. Figure 2 showed a lack of correlation between the RF levels and the age of secreting subjects $(\mathrm{R}=0.04)$. This lack of correlation confirms the results in Table 2 related to the distribution of the mean level of RF according to age, which showed a statistically insignificant difference. Figure 3 revealed that the RF level was inversely proportional to parasite density. There was a statistically significant negative correlation $(R=-0.65, p$ $<10^{3}$ ). This negative correlation confirms the results in Table 3 that showed a statistically significant difference between the highest mean level of RF for parasite densities below $60000 \mathrm{Tpz} / \mu 1$ compared to those above $60000 \mathrm{Tpz} / \mu 1$. By distributing secreting subjects of RF in two age groups $(<5$ and $\geq 5$ years), it has always been noted the same statistically significant negative correlation between parasite density and RF level. However it was found that this negative correlation was stronger in subjects whose age was superior or equal to 5 years (Figure $5, \mathrm{R}=-0.53, \mathrm{p}=0.006$ ) compared to those who were under 5 years (Figure $4, \mathrm{R}=-0.23, \mathrm{p}=0.013$ ).

Table 1. Distribution of patients according to gender, rheumatoid factor,its levels and parasite density.

\begin{tabular}{|c|c|c|c|c|}
\hline $\begin{array}{l}\text { Rheumatoid } \\
\text { factor (RF) }\end{array}$ & Males & Gender & Females & Total \\
\hline Positive & $27(69.23 \%)$ & & $12(30.77 \%)$ & $39(100 \%)$ \\
\hline RF level (UI/ml) & 12.89 & & 12.67 & - \\
\hline $\begin{array}{l}\text { Parasite density } \\
(\mathrm{Tpz} / \mu \mathrm{l})\end{array}$ & 54813.21 & & 47815.45 & - \\
\hline Negative & $43(47.25 \%)$ & & $48(52.75 \%)$ & $91(100 \%)$ \\
\hline Total & 70 & & 60 & 130 \\
\hline
\end{tabular}

Table 2. Distribution of patients $R F+$ according to age and RF levels and parasite density.

\begin{tabular}{lll}
\hline Age (years) & $<\mathbf{5}$ years & $\geq \mathbf{5}$ years \\
\hline Number of $\mathrm{RF}+$ & $23(58.97 \%)$ & $16(41.03 \%)$ \\
$\mathrm{RF}$ level $(\mathrm{UL} / \mathrm{ml})$ & 14.09 & 11.00 \\
Parasite density $(\mathrm{Tpz} / \mu \mathrm{l})$ & 51980 & 47437.50 \\
\hline
\end{tabular}

Table 3. Distribution of patients $R F+$ according to parasite density and $R F$ levels.

\begin{tabular}{lll}
\hline Parasite density $(\mathrm{Tpz} / \boldsymbol{\mu l})$ & $<\mathbf{6 0 0 0 0}$ & $\mathbf{2 6 0 0 0 0}$ \\
\hline Number of RF+ & $22(56.41 \%)$ & $17(43.59 \%)$ \\
RF level $(\mathrm{UI} / \mathrm{ml})$ & 14.73 & 10.35 \\
\hline
\end{tabular}

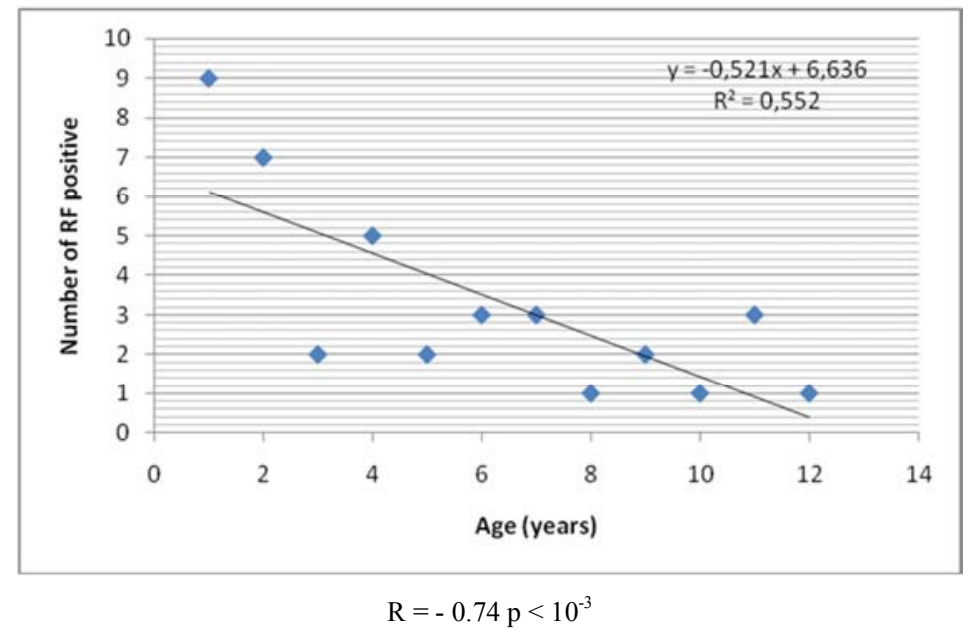

Figure 1. Relationship between numbers of patients $R F+$ and age.

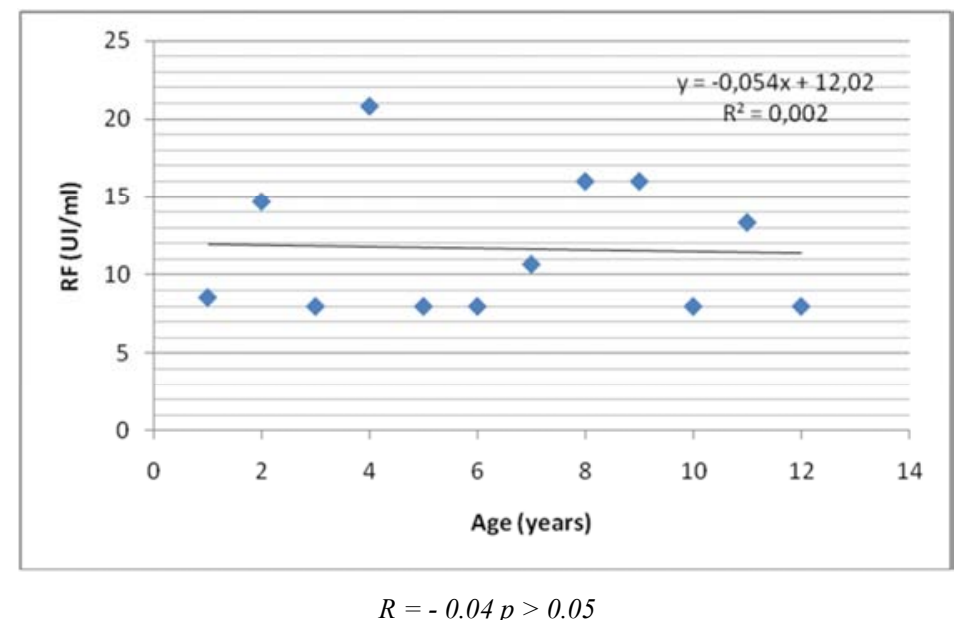

Figure 2. Relationship between $R F$ levels and age in patients $R F+$. 

Its Association with Gender, Age and Parasite Density

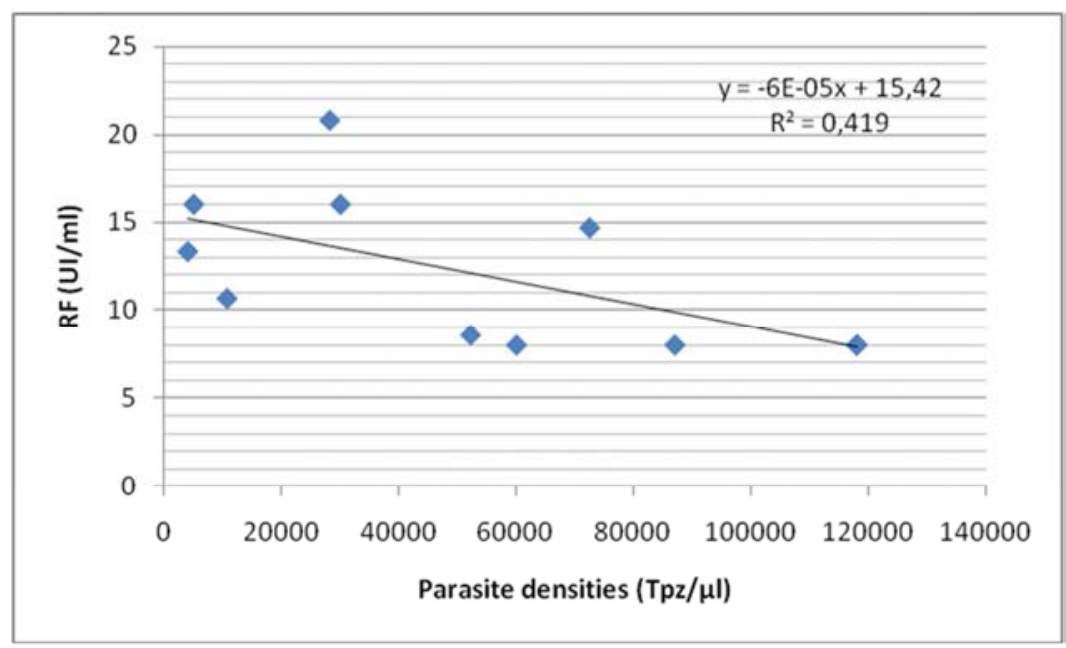

$$
R=-0.65 p<10^{-3}
$$

Figure 3. Relationship between $R F$ levels and parasite densities in all patients $R F+$.

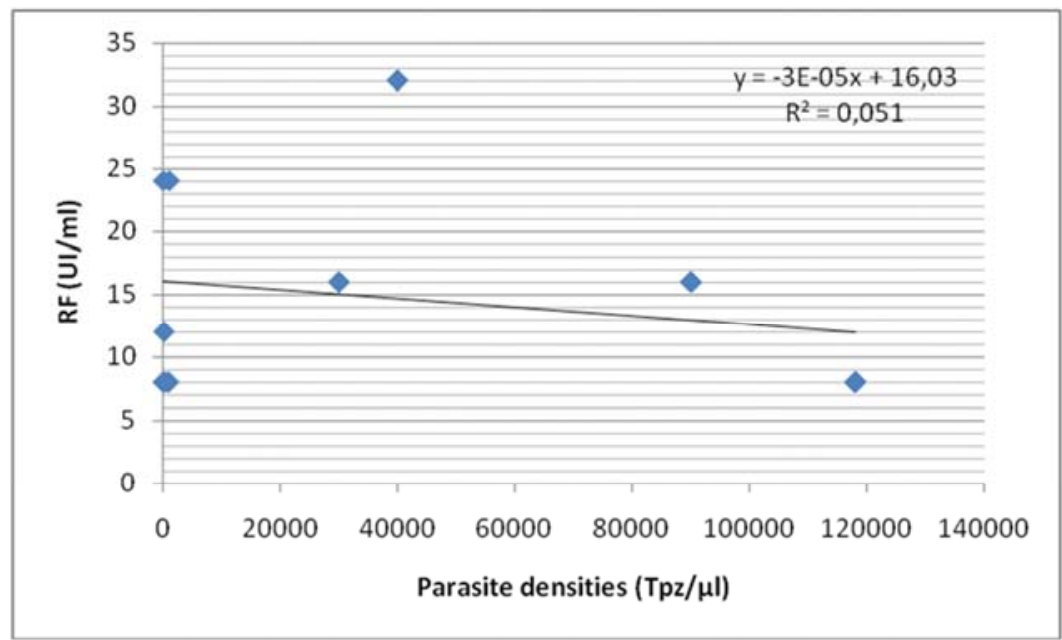

(Age $<5$ years) $R=-0.23 p=0.013$

Figure 4. Relationship between $R F$ levels and parasite densities in patients $R F+$.

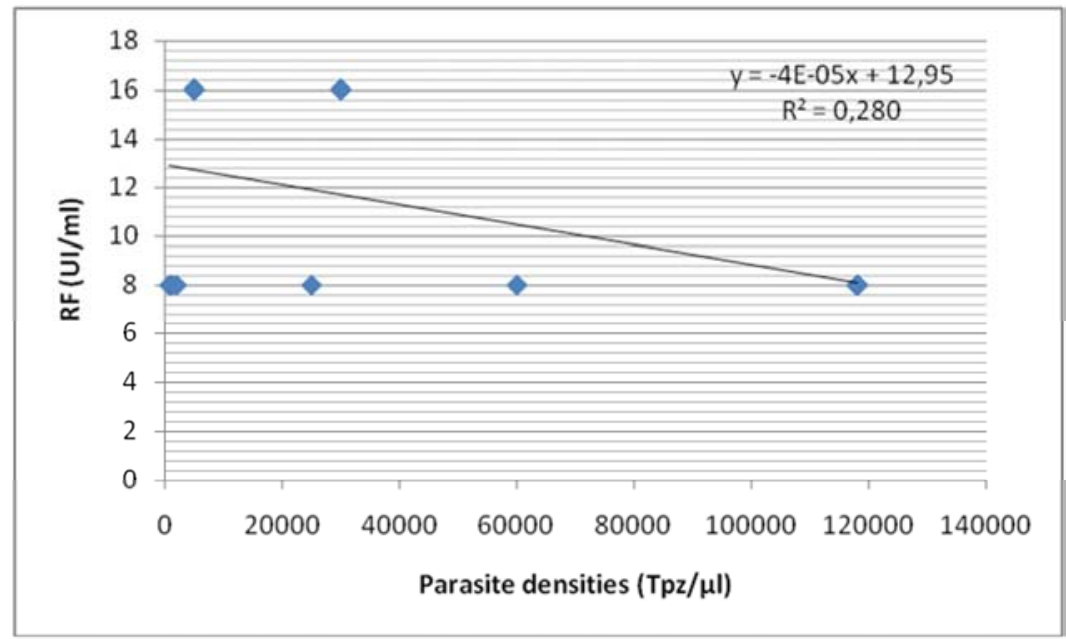

(Age $\geq 5$ years). $R=-0.53 p=0.006$

Figure 5. Relationship between $R F$ levels and parasite densities in patients $R F+$. 


\section{Discussion}

The mean level of thrombocytes in the study population was inferior to $150000 / \mu 1$, reflecting thrombocytopenia. However leukocytes mean level was normal as revealed the work of Imoru et al in Nigerian children with falciparum malaria [16]. In fact the standard level of leukocytes of the age group studied varies between $6 \times 10^{3} / \mu 1$ and $13.5 \times 10^{3} / \mu 1$ [17]. The results of Figure 1 and Table 2 showed that age would influence the incidence of rheumatoid factor secretion butwould not influence its secretion levels (Figure 2 and Table 2). Unlike the results of Sombo et al, [18], we observed prevalence 4 times higher (30\%) in our study population. All the patients $\mathrm{RF}+$ were suffering from severe malaria but it did not allowed us to consider that RF secretion was only observed in subject suffering from severe malaria May be a comparative study must be done, in patients $\mathrm{RF}+$ with severe and uncomplicated malaria. In contrast we also found that males ran more risk of secreting RF than females (Table 1, $\mathrm{OR}=3.35$ ), which corroborated with results of Bonfa et al. [19]. Rheumatoid factor levels were negatively correlated with parasite densities in all RF+ subjects (Figure 3). However the levels of secretion of this factor did not appear influenced by gender (Table 1). Concerning the secretion of auto-antibodies, Daniel-Ribeiro et al., have demonstrate that chronic stimulation of Plasmodium antigens, would result in the establishment of anidiotypic/anti-idiotypic network. Some anti-idiotypes carry the characteristics of autoantibodies [20] which include rheumatoid factor. Inflammation being one of the characteristics of Plasmodium falciparum malaria [21], according to Sibilia et al. [8], when chronic and important, it can cause rheumatoid factor in nearly $30 \%$ of cases, as revealed in our study. The Table 3 showed that parasite density would influence the level of RF. The Figures 3, 4 and 5, about the decrease of rheumatoid factor levels correlated with parasite densities, confirms this influence. This correlation was higher in older subjects $(\geq 5$ years). Age could therefore influence this correlation. In contrast, the work done by Sombo et al [18] about healthy subjects from 3 to 67 years living in a malaria-endemic area had revealed a positive correlation between RF level and parasite density. About this negative correlation between levels of RF and parasite densities, we found no explanation, but we suspected immune auto-regulation mechanism. The differences observed between the above results of Sombo et al [18] compared to ours might be due to the fact that our study population consisted of only children living in an endemic area but also suffering from malaria.

\section{Conclusion}

The determination of rheumatoid factor in children from 0 to 15 years with Plasmodium falciparum malaria, revealed that $30 \%$ of these children secrete this factor and that the age group less than 5 years, which remains the most susceptible to malaria accounted for $58.97 \%$ of secreting subjects. The incidence of secretion of RF and its levels were negatively correlated respectively to age and parasite density. The gender does not appear influence the level but males had 3.35 times higher risk of secreting RF compared to females during malaria. A work has been done in our laboratory about healthy subjects from 3 to 67 years living in a malaria-endemic area which had revealed a production of rheumatoid factor especially in the age group from 3 to 13 . This one in children from 0 to 15 years suffering from falciparum malaria has helped clarify that the majority of subjects secreting rheumatoid factor were less than 5 years and this autoantibody was associated with gender, age and parasite density.

\section{References}

[1] Biommis Facteurs rhumatoïdes, in Précis de biopathologie analyses médicales spécialisées; 2012.

[2] Qingfeng Zhang, T. Nicolai Siegel, Rafael M. Martins et al. Exonuclease-mediated degradation of nascent RNA silences genes linked to severe malaria. Nature. 2014, 513: 431-435.

[3] Dassé S. R., Akré D. P., N'guessan K., Sombo M. F. Les anticorps antinucléaires (aan) au cours de l'accès palustreRev. Int. Sc. Méd. 2006, 8; 2: 23-27.

[4] Akré D. P., Séka S. J., Dassé S. R. et al. Recherche d'autoanticorps antierythrocytairesau cours de l'accespalustre chez 50 enfants au chu de cocody. J. sci. pharm. biol.2007, 8; 1: 78-84.

[5] Houba V, Page Faulk W and Y. Matola G Heterophilic antibodies in relation to malarial infection: population and experimental studies. Clin. exp. Immunol. 1974, 18: 89-93.

[6] Phanuphak P, Suranan Tirawatnpong, Mattana Hanvanich, Panmuong W, Moollaor P, Sodsai Vejjajiva et al Autoantibodies in falciparum malaria: a sequential study in 183 Thai patients.Clin. exp. Immunol. 1983, 53: 627-633.

[7] Boonpucknavig S \& Ekapanyakul G Autoantibodies in sera of Thai patients with Plasmodium falciparum infection. Clin. exp. Immunol. 1984, 58: 77-82.

[8] Sibilia Auto-anticorps: intérêt diagnostique et pronostique en réanimation médicale. Réanimation 2002, 11: 349-58.

[9] Raymond Lepage Les problèmes de réactivité croisée et d'interférences hétérophiles dans les tests immunologiques. Ann Biol ClinQué 2005, 42; 1: 21-29.

[10] Ghosh K., Javeri K. N., Mohanty D., Parmar B. D, Surati R. R., Joshi S.H. False-positive serological tests in acute malaria. Br J Biomed Sci. 2001, 58;1: 20-23.

[11] Lewis JG, Florkowski CM, Elder PA, Hunt PJ. Rheumatoid factor and false positive sex-hormone binding globulin. ClinChimActa 2003, 332:139-41.

[12] Bjerner J. Human anti-immunoglobulin antibodies interfering in immunometric assays. Scand J Clin Lab Ivest 2005, 65: 349-64.

[13] Sapin R Interferences in immunoassays: Mechanisms and outcomes in endocrinology Annals of Endocrinology 2008, 69: 415-425. 
[14] Néraud B, Leroy-Billiard M, Soudan B, Dewailly D Interférences hétérophiles dans les dosages immunologiques: une cause d'erreur à ne pas méconnaître. mt médecine de la reproduction 2006 , vol. $8, \mathrm{n}^{\circ} 5$.

[15] Dassé SR, N'guessan K, Akré DP, Kouamé DR, Yeboah OR, Sombo MF Facteur rhumatoïde et tests de diagnostic sérologique en zone d'endémie du paludisme. Afrique Biomédicale 2011, 16; 4: 62-67.

[16] Imoru $M$, Shehu $U$ A, Ihesiulor $U$ G, kwaru A H. Haematological changes in malaria-infected children in NorthWest Nigeria. Turk J Med Sci 2013, 43: 838-842.

[17] KANAKIA Health Express Reference ranges for leucocyte count in children. February 2006; Vol. $2 \mathrm{~N}^{\circ} 6$.

[18] Sombo MF, Dassé SR,Akré DP, N'guessan K,Sangaré MA Fréquence du facteur rhumatoïde chez les sujets sains vivant dans une zone d'endémie palustre.Rev. Int. Sc. Méd. 2006, 8; 2:13-17.

[19] Bonfa E., Llovet R., Scheinberg M., De Souza J. M., Elkon K. B. Comparison between auto antibodies in malaria and leprosy with lupus. Clin exp. Immunol. 1987, 70;3: 529-37.

[20] Daniel-Ribeiro C., Deslandes D. C., Ferreira-Dacruz Mde F. J. Cross-reactions between idiotypes, Plasmodium falciparum derived peptides, dinitrophenyl and beta (2-->6) polyfructosan. Clin Lab Immunol. 1991, 36; 1: 23-6.

[21] Sarah EC, James MT, Mahdi R, Jape K J, Sunil S, Robert EB and Rebecca JS Inflammation is strongly associated with Plasmodium falciparum malaria and predicts erythropoietin, soluble transferrin receptor, and zinc protoporphyrin concentrations in severely anemic Zanzibari preschoolchildren. TheFASEB Journal 2008, 22:873.12. 